\title{
CHILD BENEFIT PAYMENTS AND HOUSEHOLD WEALTH ACCUMULATION
}

\author{
By MELVIN STEPHENS Jr $\dagger$ and TAKASHI UNAYAMA $\dagger$ \\ $\dagger$ University of Michigan and NBER \$Hitotsubashi University
}

\begin{abstract}
Using the life-cycle/permanent income hypothesis, we theoretically and empirically assess the impact of child benefit payments on household wealth accumulation. Consistent with the predictions of the model, we find that higher cumulative benefits received increase current assets, higher future benefit payments lower asset holding, and that these effects systematically vary over the life cycle. We find different wealth responses to child benefit payments for liquidity constrained and unconstrained households, as predicted by the model.

JEL Classification Numbers: D12, E21.
\end{abstract}

\section{Introduction}

Child benefits, or cash transfers to families based solely on the number and/or age of their co-residing children, are prevalent in a number of industrialized countries. The exact policy goals that governments aim to achieve by providing these benefits vary, which is reflected in the differences in the structure of these benefits across countries. Means-tested benefits lead to relative improvements in household resources for low income families while higher benefit amounts for higher parity children offer a path to achieve pro-natalist aims. ${ }^{1}$

In Japan, the child benefit system (or jidou teate in Japanese) was introduced in 1972 as an important component of social security programmes. ${ }^{2}$ The Child Benefit Act states that its goal is to contribute toward "stable family life" and "healthy upbringing of children" by making benefit payments to the parents and guardians of children. ${ }^{3}$ Thus, policy-makers likely had in mind that these benefits would immediately increase consumption upon receipt, although the aforementioned quotes certainly do not rule out saving the benefits to offset adverse events or to provide for their children's future expenses.

In this paper, we examine the impact of the Japanese child benefit system on household wealth accumulation. Within the context of the standard life-cycle/permanent income model, regardless of the exact policy aims of the benefits, the contemporaneous impact of these benefits on household consumption and savings is unclear. On the one hand, these benefits may primarily be saved because the duration of benefit payments is limited and so they are treated as transitory income. ${ }^{4}$ In fact, a recent survey by Japan's Cabinet Office

1 Van Lancker et al. (2012) provide an overview of child benefits in a number of European countries.

2 Jidou teate is sometimes translated as "child allowance", but hereafter we use "child benefit" for consistency.

3 Article 1 of the Child Benefit Act. See http://law.e-gov.go.jp/htmldata/S46/S46HO073.html (in Japanese).

4 Moreover, families may believe, in a Ricardian equivalence sense, that the future tax liabilities necessary to finance current benefits requires them to save most of the benefit to offset future tax increases, including increased bequests to heirs (Barro, 1974). 
finds that nearly $50 \%$ of Japanese households explicitly save the benefit for the child's future (Japan Times, 2010). On the other hand, however, liquidity-constrained households may find it advantageous to use these benefits to increase current consumption and, therefore, save little or none of the benefit.

Using a basic life-cycle/permanent income hypothesis framework, we derive a number of predictions for the impact of child benefits on household wealth accumulation. Because most of the benefit will be saved, household wealth increases with the total amount of benefits that have already been received. In addition, because expected future benefits increase current consumption, household wealth is a decreasing function of expected future benefits. The model also yields a testable restriction on the parameters of the wealth equation on benefits received to date and expected future benefits, which reflect the marginal propensities to save and spend out of benefit payments.

To test these theoretical predictions, we exploit a number of changes in child benefit eligibility and benefit amounts. Benefits were initially only available for families with three or more children, before opening up to families with at least two children in 1986 and, finally, to single-child families in 1992. In addition, benefits were initially paid until the child reached age 15 , although the benefit payment period was drastically reduced to up to age 3 in 1992 before gradually being increased back to age 15 by 2010 . Furthermore, benefit levels were substantially increased beginning in the mid-1990s. The resulting combinations of reforms generate substantial variation in the benefits received by households, as well as the expected future benefits, and allow us to estimate the impact of child benefits on household wealth accumulation.

Using data on household wealth collected as part of the Japanese Family Income and Expenditure Survey (JFIES), we estimate the impact of child benefits received on household wealth. Consistent with the model predictions, we find that cumulative benefits received to date increase household assets, while increases in future benefits reduce the stock of wealth. We cannot reject the restriction that the sum of the coefficients on benefits paid to date and expected future benefits in the household wealth equation should be one, which is implied by the model. We also find evidence consistent with another prediction of the model that those coefficients change systematically over the life cycle, although alternative specifications yield mixed evidence. In addition, we present results separately by asset class and find that most of the increase occurs in illiquid assets such as life insurance, stocks ("equity") and "time deposits".

Finally, the predictions from the basic life-cycle model are strongly aligned with our findings for a subsample of households that likely do not face liquidity constraints in that the benefits are mostly saved. Our results for constrained households are strikingly different from those of the unconstrained households, although our findings for the constrained subsample are only partially consistent with the predictions for these households based on the life-cycle model.

Our examination of household wealth is a departure from most of the prior literature that has examined the effects of child benefits. Previous papers have examined the impact of child benefits on fertility decisions (Milligan, 2005; Cohen et al., 2013; González, 2013) and child well-being (Milligan and Stabile, 2009, 2011). González's paper is the most closely related to ours in that she examines the impact on consumption and labour supply albeit in response to a one-time fertility payment for new births in Spain that began in July 2007. Using a regression discontinuity design, she finds that Spanish households did not change their total expenditure at the time when births became eligible for payments. However, she finds a reduction in the work effort of mothers for the first year after child 
birth and a corresponding decline in daycare expenditures. Taken together, her results suggest that families "spent" the benefit on increased non-market time of the wife, although the effect on savings is not investigated.

Our study also contributes to the vast literature that tests the life-cycle/permanent income hypothesis. Studies examining how households respond to transitory income shocks typically use the Euler equation framework to test whether consumption changes respond to income changes (e.g. see the studies cited in the survey by Jappelli and Pistaferri, 2010). Campbell's (1987) insightful approach uses the model to yield predictions for how annual savings flows respond to changes in expected future income. We do not have information on annual savings flows but, rather, extensive details on the stock of household wealth. To take advantage of this data, we derive implications for how transitory income payments, both past and future, affect the stock of wealth within the life-cycle/ permanent income framework. As such, our approach is complementary to the prior literature.

The paper is set out as follows. The next section discusses the history of Japan's child benefit system, including the variation in benefit eligibility and payment amounts that we will exploit in our empirical analysis. The following section examines the theoretical implications of child benefit payments on wealth, the data that we use in our analysis and our empirical specification. We then turn to our empirical results before concluding in the final section.

\section{Japan's child benefit programme}

The child benefit system was introduced in 1972 as an important component of Japan's social security programmes. The Child Benefit Act states that its goal is to contribute toward "stable family life" and "healthy upbringing of children" by making means-tested benefit payments to the parents and guardians of children, although the effective objective has been changed over time. In the 1970s, the benefit was a pro-natalist policy focusing on households with many (three or more) children. In the mid-1980s, it worked as a device for redistribution between generations to compensate for the public pension premium required under the pay-as-you-go pension system which was introduced in 1985. After the 2000 revision, the act again became one of the countermeasures to the falling birth rate. Reflecting these changes in the policy purpose, benefit eligibility and amounts have varied over time based on the number and ages of children.

As shown in Table 1, which displays a brief history of the Child Benefit Act, the scope of the act has been expanded twice with regards to the child parity at which the household becomes eligible for benefits. Households with at least three children have been beneficiaries of child benefits since the programme's inception. In 1986, families with two or more children became eligible to receive benefits. Families with one child became eligible to receive benefits in 1992. Not surprisingly, these changes increased the incidence of benefit receipt among younger parents.

The child ages at which benefits are distributed have also changed over time. While the age threshold for benefits was 15 when the system was introduced, the age threshold was reduced to 3 when the first child became eligible in $1986 .{ }^{5}$ However, since policy-makers

\footnotetext{
The effective eligible age was 5 years in 1972 and 10 years in 1973 as a transition.
} 
TABLE 1

History of child benefit law in Japan

\begin{tabular}{|c|c|c|c|c|c|c|}
\hline \multirow{2}{*}{$\begin{array}{l}\text { Law change } \\
\text { Year }\end{array}$} & \multicolumn{2}{|c|}{ Eligible child } & \multicolumn{3}{|c|}{ Monthly benefit ( 1,000 yen) } & \multirow[b]{2}{*}{ Earnings test? } \\
\hline & Birth order & Age limit & First/second child & Third + child & Age $<3$ & \\
\hline 1972 & Third and later & $15^{\ddagger}$ & & 3 & & Yes \\
\hline 1974 & Third and later & $15^{\ddagger}$ & & 4 & & Yes \\
\hline 1975 & Third and later & $15^{\ddagger}$ & & 5 & & Yes \\
\hline 1986 & Second and later & $6^{\S}$ & 2.5 & 5 & & Yes \\
\hline 1992 & All & 3 & 5 & 10 & & Yes \\
\hline 2000 & All & $6^{\pi}$ & 5 & 10 & & Yes \\
\hline 2004 & All & 9 & 5 & 10 & & Yes \\
\hline 2006 & All & $12^{\dagger \dagger}$ & 5 & 10 & & Yes \\
\hline 2007 & All & 12 & 5 & 10 & 10 & Yes \\
\hline $2010^{\ddagger \ddagger}$ & All & $15^{\ddagger}$ & 13 & 13 & & No \\
\hline $2011^{\text {ศा }}$ & All & $15^{\ddagger}$ & 13 & 13 & & No \\
\hline 2012 & All & $15^{\ddagger}$ & 10 & 15 & 15 & Yes \\
\hline
\end{tabular}

Notes: The law change year indicates the year of enforcement. Transitional provisions were introduced for every law change. ${ }^{\star}$ Before completing the junior high school. ${ }^{\circledR}$ Before entering the elementary school. "Until 3rd

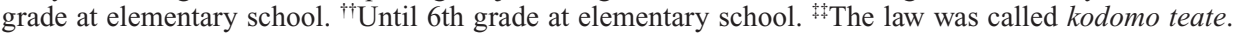

have decided to use child benefit payments to encourage higher fertility, the age limit has been raised repeatedly. The age cutoff increased to 6 in 2000, to 9 in 2004, to 12 in 2006, and to 15 in 2010.

Child benefit payments have undergone long periods during which the benefit amounts remained fixed in nominal terms as the benefits have never been indexed to prices. In the 1970s and early 1980s, the benefit levels were gradually increased but effectively remained stable in real terms. Beginning in 1992, benefits were set at 5,000 yen per month for first and second children and at 10,000 yen for each additional child. In 2006, the monthly benefit amount was set at 10,000 yen regardless of parity but only until age 3 . Benefits were significantly increased between 2010 and 2012, when the Democratic Party of Japan (DPJ) was in power and the system was called kodomo teate in Japanese. Benefit levels were subsequently decreased after this period, but still higher than in the pre-DPJ period, and the Japanese name of the act was changed back to jidou teate.

These frequent changes generate large differences in the lifetime benefits received among close birth cohorts, as is shown in Figure 1. For example, a family's first child who was born in 1986 was never eligible for benefits, while the cumulative benefits for a first child born in 1990 totalled 120,000 yen (roughly US\$1,000). A first child born in 1997, not too many years later, is eligible for 15 years of benefit payments, totalling more than 1 million yen (approximately US\$10,000).

To provide an alternative view on how benefit levels evolve over time, Figure 2 shows, by the birth year of the oldest child, the ratio of annual household child benefits to yearly income averaged across all JFIES families with children. ${ }^{6}$ For families in which the oldest child was born in the 1970 s, benefits represent less than $1 \%$ of annual family income. For

6 Due to low levels of reporting of child benefits in the JFIES, we construct annual benefit amounts rather than using reported benefit payments. These values account for the means-testing feature of the programme. We provide more details on the computation of these benefits in the next section. 


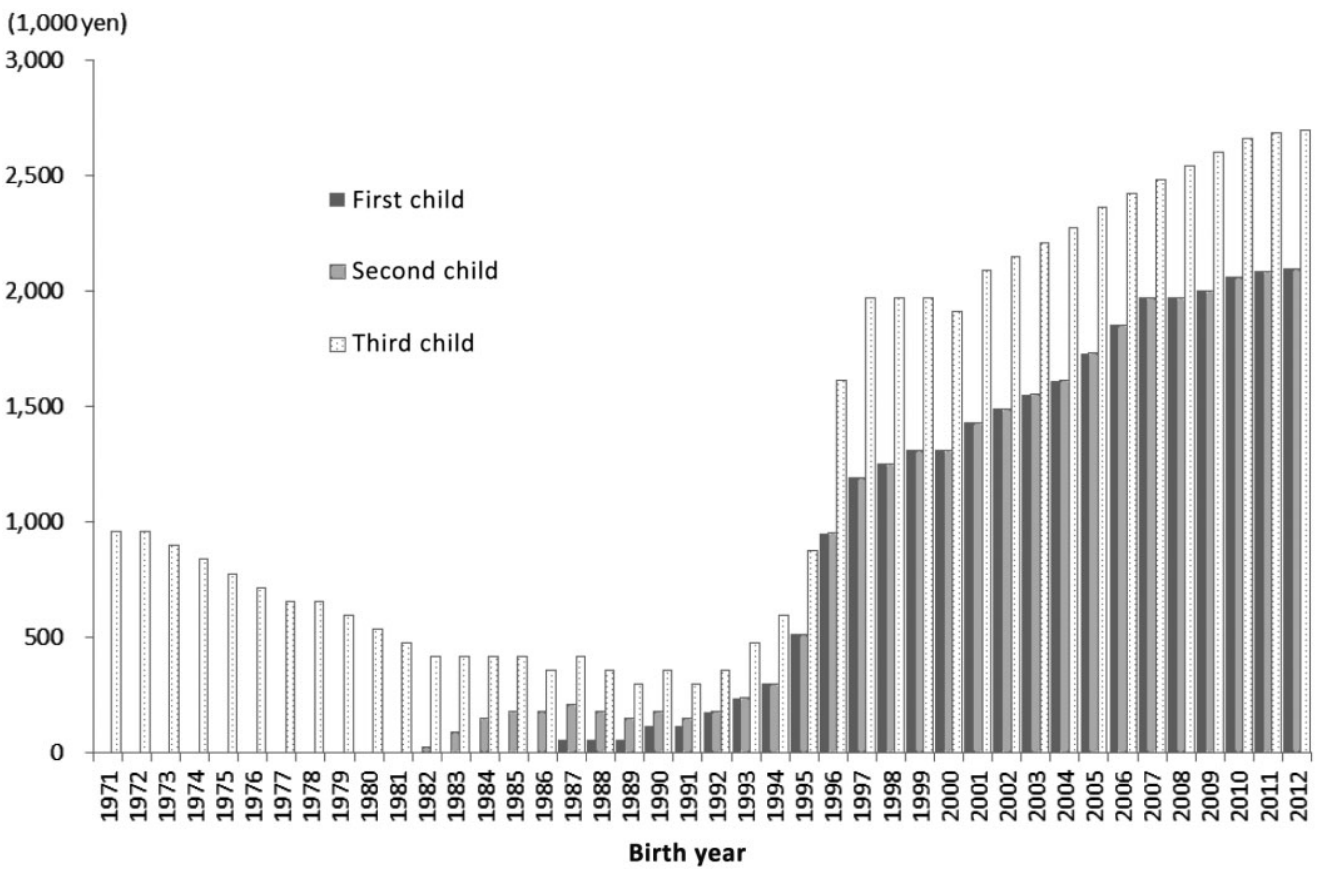

FIGURE 1. Total amount of child benefit by birth year.

Notes: The amount of benefits are calculated by applying the law at each point of time to age(s) of child(ren). We assume there is no law change after 2013.

oldest children born in the 2000 s, benefits are over $3 \%$ of annual income. Prior work by Browning and Crossley (2001) suggests that it is not costly in terms of lifetime utility to deviate from the life-cycle model when payments induce small fluctuations to annual income. Based on their insights, it would not be surprising to find evidence rejecting the life-cycle model with respect to child benefit payments.

\section{The impact of child benefit payments on wealth}

\subsection{Theoretical framework}

To understand the impact of child benefit payments on wealth, we examine a finite-lived household's maximization problem. Assuming that utility is intertemporally separable, $\delta$ is the rate of time preference and $r$ is a constant interest rate; households choose consumption, $C_{t}$, in each period $t=1,2, \ldots, T$ to maximize utility over the remainder of their lifetime

$$
E_{t} \sum_{j=0}^{T-t}\left(\frac{1}{1+\delta}\right)^{j} U\left(C_{t+j}\right)
$$

subject to the equation for the evolution of assets (after receiving income but before choosing consumption), $A_{t}$, 


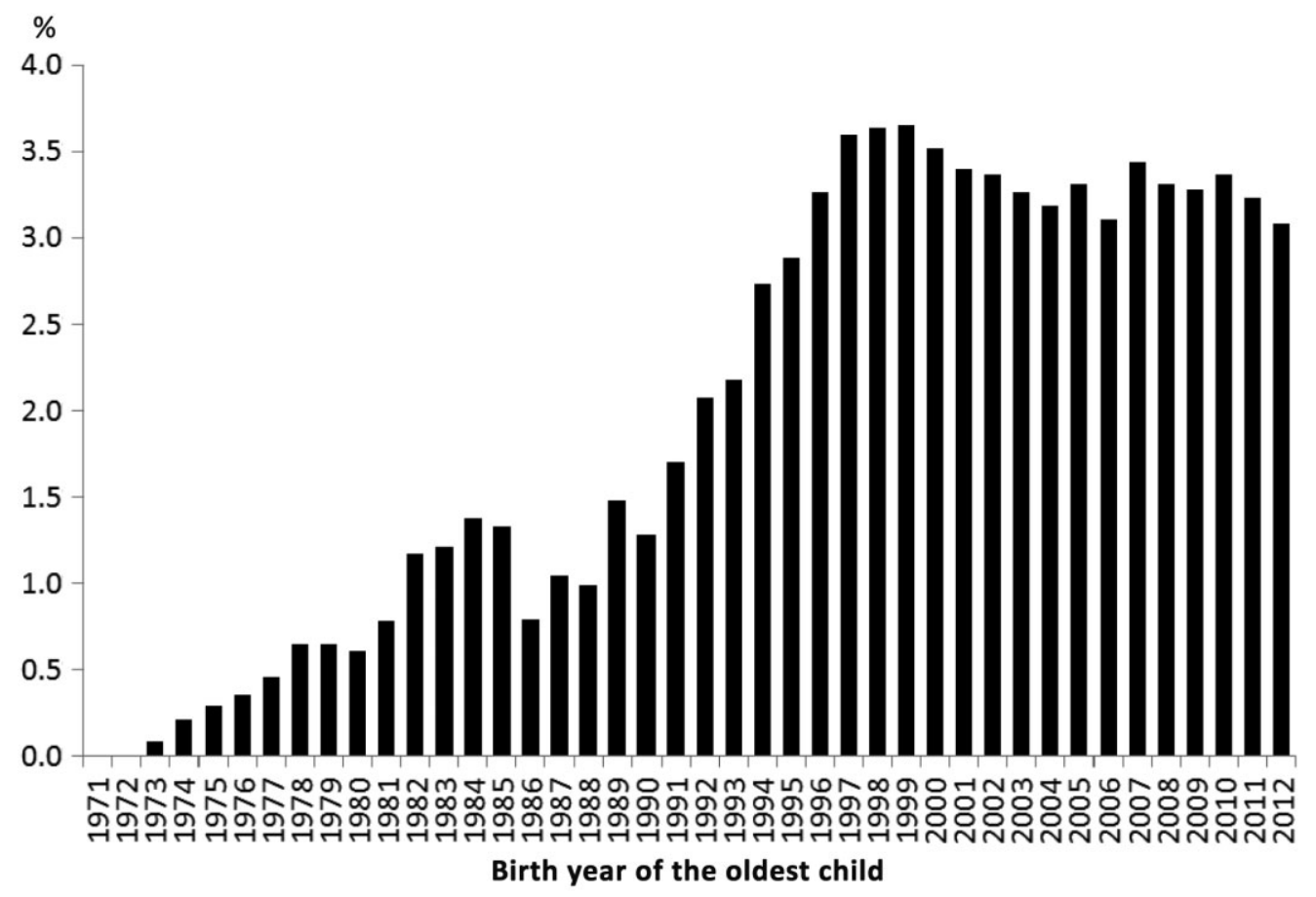

FIGURE 2. Ratio of annual benefits to income by oldest child birth year.

Note: The ratio is calculated by dividing imputed annual benefits by yearly income reported by households.

$$
A_{t+1}=(1+r)\left(A_{t}-C_{t}\right)+Y_{t+1}
$$

where $Y_{t}$ is income in period $t$ and $T$ is fixed. As shown in Zeldes (1989b) and Carroll (1997), under the assumptions that the period-specific utility function exhibits constant relative risk aversion, $r=\delta$, and future income is known, the solution for consumption in each period is

$$
C_{t}=k_{t}\left[A_{t}+H_{t}\right]
$$

where

$$
k_{t}=\left(\frac{r}{1+r}\right)\left[\frac{1}{1-(1 / 1+r)^{T-t+1}}\right]
$$

and

$$
H_{t}=\sum_{j=1}^{T-t}\left(\frac{1}{1+r}\right)^{j} Y_{t+j} .
$$

Optimal consumption in each period is a proportion, $k_{t}$, of current period assets, $A_{t}$, and future income, $H_{t}$. Thus, $k_{t}$ is the annuity value of lifetime wealth, which further simplifies to spending a constant share in each period of $k_{t}=1 /(T-t+1)$ when $r=0$. 
The effect of child benefit payments on consumption in each period follows directly from Equation (3). Suppose that households receive an annual child benefit payment of $P$ for a total of $C<T$ years, beginning at $t=1$, such that lifetime child benefits received are $L C B=C P .{ }^{7}$ Assuming $r=0$, the child benefit increases consumption by a constant amount $L C B / T=C P / T$ in each period.

As shown in Figure 2, child benefit payments, $P$, range from 1 to 3\% of annual income. If these benefits were received every year for the rest of the household's lifetime (i.e. if $C=T$ ), then the model would predict a permanent increase in consumption of the same magnitude. However, given that benefits are only received from 3 to 15 years of age, the predicted increase in consumption, which is proportional to $C / T$, is far smaller. Such small changes in consumption are likely difficult to find in monthly consumption data, especially given the reporting errors found in survey data. ${ }^{8}$

By the same token, the model implies that payments should be mostly saved, especially if the benefits are only paid for a short period of time. During the years that families are receiving benefit payments, household wealth increases as households continue to primarily save their benefit payments. Thus, while benefit payments may have little effect on consumption, if households are behaving in a manner consistent with the model then the impact on the stock of wealth is potentially quite sizable.

We can determine the impact of child benefits on the accumulated assets in period $t, C B A_{t}$, which is the difference between total child benefits paid to date, $P B_{t}$, and the total spending increase to date due to the child benefit, $T S_{t}$. Given our assumption that benefit payments begin in period 1 , total benefits paid to date are $P B_{t}=\min (t P, L C B)$, which accounts for the cap in lifetime benefits of $L C B$. Total spending to date, assuming $r=0$, is the sum of the constant spending amount over the first $t$ periods, $T S_{t}=t \cdot(C P / T)=(t / T) \cdot L C B$. Thus, the amount of the child benefit received to date that should be saved for future spending is

$$
C B A_{t}=P B_{t}-(t / T) \cdot L C B
$$

Notice that we can further simplify this last expression by noting that the lifetime child benefits, $L C B$, are the sum of child benefits paid to date, $P B_{t}$, and expected future child benefit payments, $F B_{t}$, or, $L C B=P B_{t}+F B_{t}$. Inserting this definition into Equation (6) yields:

$$
\begin{aligned}
C B A_{t} & =P B_{t}-(t / T) \cdot L C B \\
& =P B_{t}-(t / T) \cdot\left(P B_{t}+F B_{t}\right) \\
& =(1-(t / T)) P B_{t}-(t / T) F B_{t} .
\end{aligned}
$$

7 This formulation of the problem ignores the possibility of future benefits changing due to having more children, children ageing out of the programme and anticipated programmatic changes. It also assumes that benefit payments begin in the first period. We restrict $C<T$ because when $C=T$ child benefits are simply a permanent increase in income and spending will increase by $P$ every period and, thus, the impact on saving will be zero. However, this simple approach highlights the main insights that we test in our empirical investigation below while keeping the notation as simple as possible.

8 Stephens and Unayama (2015) finds that only one-quarter of eligible households correctly report receiving the child benefits. 
This expression for the amount of child benefits saved for subsequent spending yields a number of implications, all of which we test in our analysis below. ${ }^{9}$ First, assets are increasing in benefits paid to date, $P B_{t}$, because $1-(t / T)>0$, and are decreasing in the amount of expected future benefits to be paid, $F B_{t}$. This result is a standard implication of the basic life-cycle model in which households spread lifetime benefits equally across all periods. Increases in past benefits lead to more saving due to the desire to increase both current and future spending. Similarly, increases in future expected benefits, holding constant past benefits received, yield higher spending to date and, thus, reduce accumulated assets.

Second, these effects systematically vary with the age of the household. Because households spend a constant fraction of lifetime benefits in each period, the share of child benefits received to date that remain unspent, $1-(t / T)$, is decreasing with age. The positive effect of benefits received to date falls as $t$ increases, while the negative effect of future benefits increases in magnitude (i.e. becoming more negative) as $t$ grows.

Third, the difference between the parameters multiplying $P B_{t}$ and $F B_{t}$ is $(1-(t / T))-[-(t / T)]=1$. This equality is due to the fact that in the basic life-cycle model, households spend a constant proportion, $1 / T$, out of lifetime child benefits, $L C B$, in each period. Whether or not these benefits have yet to be paid, i.e. whether in $P B_{t}$ or $F B_{t}$, is irrelevant to the household's decision in the model and, thus, yields the relationship between the coefficients on these two measures of benefit payments. Alternatively, because the coefficients on $P B_{t}$ and $F B_{t}$ are the propensity to save out of paid benefits and (the negative of) the propensity to spend out of future benefits, respectively, and because households treat past and future benefits equally in their decisions, these two propensities should sum to one.

Finally, the responses we have described above assume that households do not face credit market constraints. The behaviour of households facing liquidity constraints no longer follows the standard Euler equation. Instead, the inability to smooth consumption by borrowing from future income raises the marginal utility of current consumption (Zeldes, 1989b). Constrained households will consume most, if not all, income depending on the magnitude of the payment. As such, we would expect increases in $P B_{t}$ to have no impact on the current stock of wealth among constrained households. However, a large enough increase in $P B_{t}$ could alleviate the constraints on some households, in which case $P B_{t}$ may have an effect on wealth. Similarly, while increases in $F B_{t}$ cannot increase the current consumption of constrained households, it is possible that large enough increases in $F B_{t}$ lead to previously unconstrained households becoming constrained. ${ }^{10}$ Thus, we expect the wealth response to $P B_{t}$ and $F B_{t}$ to be zero for constrained households, except for those households that have changed from constrained to unconstrained, or vice versa, due to changes in benefit payments. ${ }^{11}$

Our approach to testing the life-cycle/permanent income hypothesis is most closely related to that of Campbell (1987). Based on the infinitely-lived consumer version of

9 Implicit in Equation (7) is that past and future benefit amounts are appropriately discounted to year $t$. In our empirical work, we make these adjustments as we discuss below.

10 For example, upon learning of a future bequest, net savers may want to become net borrowers but may be constrained from doing so.

11 While the benefit increases were likely not large enough to cause many households to change constrained status, we raise these possibilities primarily to note that the model predictions are not as straightforward for constrained households as they are for unconstrained households. 
Equation (3) and noting that in each year income equals consumption plus saving, Campbell derives an equation for the annual savings flow as a function of changes in expected future income. Building upon Campbell's insight, we derive predictions for how child benefit payments, both past and future, affect the current stock of wealth. Alternatively, we could examine the impact of child benefit payments on consumption. However, each additional yen in benefits, whether past or future, increases current consumption by $1 / T$ annually (or $1 /(12 \cdot T)$ monthly), meaning that there is no difference in the response between $P B_{t}$ and $F B_{t}$. While this result yields a testable restriction, it is also the case that the predicted increase in consumption is quite small, especially at the monthly frequency for which we have consumption data in the JFIES. As such, the power to test whether or not household behaviour is consistent with the model is quite limited when exploiting differences in benefit amounts across cohorts. Instead, we utilize the predictions for the impact on wealth to test the life-cycle/permanent income hypothesis.

Before proceeding, we should note that a more standard approach to testing the lifecycle/permanent income hypothesis would be to test whether monthly consumption changes are affected by the timing of child benefit payments. Exploiting the fact that these benefits are paid only three times a year, Stephens and Unayama (2015) find a small but significant response of monthly consumption at the time child benefits are received. The findings in that paper indicate that $5-6 \%$ of child benefit payments are consumed in the month that they are received. However, this approach does not reveal whether consumption is increased across all months due to increases in child benefits as is predicted by the model. By examining wealth accumulation, we can examine longer-run responses to benefit payments, which implicitly answers the question of whether these benefits lead to a permanent increase in consumption.

\subsection{Data}

We use data from the JFIES for 1981-2010. ${ }^{12}$ The JFIES is a household survey in which respondents are asked to record all income and expenditure in a daily diary for 6 months. Prior to 2002, the JFIES only collected information on financial assets and liabilities in January for the subsample of households whose first month of participation in the JFIES was in the preceding August, September or October. This wealth survey is called the Family Saving Survey (FSS). Beginning in 2001, the FSS format was abolished. Instead, the JFIES now collects financial information from all households during their third month of participation in the survey.

For our analysis, we limit the sample to "nuclear families", which we define as a couple with co-residing unmarried children. As such, childless couples and intergenerational households are dropped because we do not have information on the ages and number of children who have left the house. We also limit our sample to households whose head is younger than age 60 because large retirement bonuses, which skew the wealth distribution, are generally distributed at this age (Stephens and Unayama, 2012).

Our analysis requires measures of the cumulative child benefits received and expected future child benefit payments as of the date that financial asset information is recorded. In principle, our knowledge of the changes in the benefit structure over time allows us to compute these amounts based on the ages of the children in the household. However, two

12 More information about JFIES can be found in Stephens and Unayama (2011). 
issues complicate this simple calculation. First, the couple may have children who have already moved out of the household, in which case we would underestimate cumulative child benefits received. To circumvent this concern, we limit the sample to households with no children over age 13. Among families with at least two children in our sample, the second child is 5 or more years younger than the oldest child in less than $9 \%$ of households. As such, limiting the oldest child to age 13 captures the vast majority of couples for whom all of their children are still living with their family.

Second, child benefits are means tested each year based on the current annual income of the household head, leading to reduced or zero benefits for high income families. We can compute the head's income for the 6 months during which the family participates in the JFIES. However, due to widespread use of bonus payments by employers, we might substantially understate the head's income if we simply double the 6-month total from the survey period. Instead, we make use of the household's annual income for the 12 months prior to survey participation, which is asked upon joining the JFIES sample. More precisely, the means test is applied to household income multiplied by 0.837 because the income of the household head accounts for $83.7 \%$ of household income on average. Using this approach, nearly $75 \%$ of children in our sample are counted as recipients, whereas more than $80 \%$ of eligible age children actually receive the benefit after 2000. Thus, we are slightly conservative in our implementation of the means test.

A related concern is that although we can determine if the household is above or below the means-testing threshold for the current year, we cannot determine whether or not the same was true in previous years. Thus, households exceeding the income threshold in the current year are assigned zero benefits for all years while households below the threshold in the current year are assumed to have been receiving benefits in all prior years. Given that household income tends to rise with age, on average, for households prior to the head's retirement, our assumption is likely not too restrictive.

Table 2 contains summary statistics for the full sample of 22,543 observations. For this table, as well as our empirical analysis, we convert all yen values to 2010 yen using Japan's consumer price index. In addition, we use the 10-year T-bill interest rate to create present values for the two accumulated measures: child benefit payments received to date and expected future child benefits. On average, households hold 1 year's worth of income in financial assets. Cumulative child benefit payments amount to roughly $10 \%$ of household wealth, while expected future child benefits are slightly higher.

Due to the changes in the child benefit programme over time, households that began having children in earlier years received smaller amounts of child benefits both because benefit levels were lower and the required parity to receive these benefits was higher. Table 3 shows that, when dividing families by the birth year of their oldest child, those families having children when benefits were higher also have higher accumulated wealth. Because these correlations are only suggestive, we next turn to our regression analysis to exploit the benefit reforms to identify the effect of child benefits on wealth.

\subsection{Empirical specification}

We estimate the impact of child benefit payments on household assets based on the implications generated by Equation (7) and accounting for the policy variation in the child benefit. Thus, the equation we estimate is 
M. Stephens Jr. and T. Unayama: Child Benefit Payments and Household Wealth Accumulation

TABLE 2

Summary statistics

\begin{tabular}{lrr}
\hline \hline Variable & Mean & $\begin{array}{r}\text { Standard } \\
\text { deviation }\end{array}$ \\
\hline Age of oldest child & 5.9 & 3.8 \\
Age of household head & 34.9 & 5.8 \\
Number of household members & 3.9 & 0.8 \\
Yearly income (1,000 yen) & 4,259 & 1,395 \\
Child benefits received to date & 379 & 447 \\
Expected future child benefits & 383 & 726 \\
Total financial asset & 4,345 & 5,138 \\
$\quad$ Deposit & 732 & 1,436 \\
Time deposits & 1,603 & 2,898 \\
$\quad$ Life insurance & 1,484 & 2,388 \\
Equity & 151 & 930 \\
Loan trust & 34 & 389 \\
Bond & 75 & 586 \\
$\quad$ Other & 175 & 717 \\
$N$ & \multicolumn{2}{c}{22,543} \\
\hline
\end{tabular}

Notes: We limit the sample to nuclear households, which consist of a couple and unmarried child(ren); the oldest child is aged 13 or under; age of household head is 60 or under; household income is lower than the threshold of the means test.

$$
A_{i, t}=\alpha+Z_{i, t} \gamma+\beta_{1} P B_{i, t}+\beta_{2} F B_{i, t}+\varepsilon
$$

where $Z_{i, t}$ includes the age of the household head, the number of household members, the age(s) of the children, year and month indicators, and an indicator for house ownership. We include a complete set of indicators for the age of the household head. To account for the age distribution of the children, we include variables for the number of children at each age from infants (i.e. age 0 ) through to age $13 .{ }^{13}$

Thus, holding constant the child age distribution and calendar year and month effects, identification of the coefficients on $P B_{i, t}$ and $F B_{i, t}$ is due to variation in the policy reforms that affect the child benefit payment structure. The theoretical model predicts that the corresponding coefficients on $P B_{i, t}$ and $F B_{i, t}$ are $\beta_{1}=1-(t / T)$ and $\beta_{2}=-(t / T)$, respectively.

A number of assumptions are required to implement our identification strategy. We assume that the number of children and the timing of child births are exogenous. We also ignore the possibility of future child benefit payment increases, due to planned increases in fertility, affecting current savings decisions. Given the evidence cited above about the impact of child benefits on fertility in other countries, these assumptions are admittedly strong. Accounting for these effects requires a dynamic structural model that is beyond the scope of this paper. Rather, we focus on testing whether observed household savings behaviour is consistent with the basic life-cycle/permanent income hypothesis.

13 The impact of the age of the children on household wealth, holding constant the age of the household head, is unclear. On the one hand, households with older children will have incurred costs associated with raising children over more years, which leads to lower wealth levels. On the other hand, households with older children may have accumulated more wealth in preparation for large future costs (e.g. college tuition). 
The Japanese Economic Review

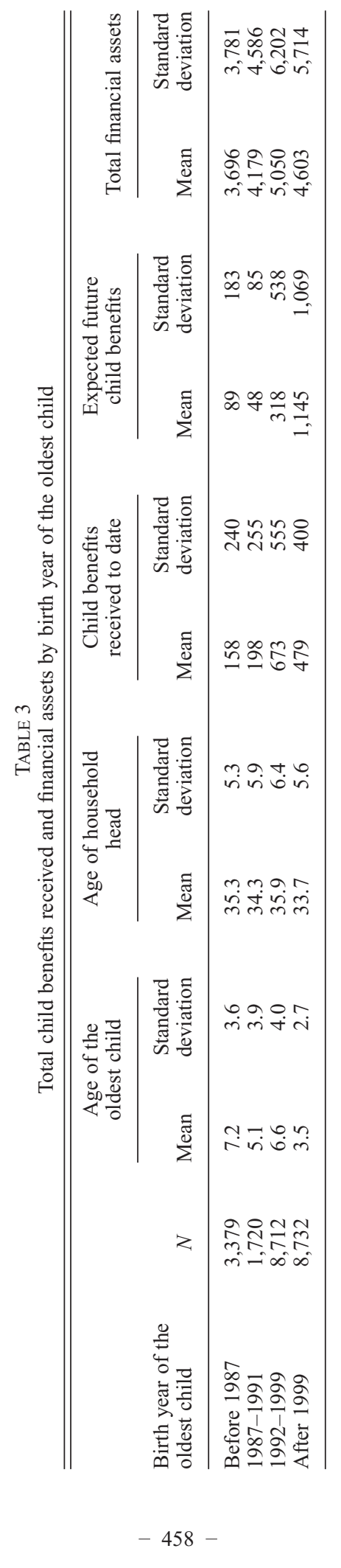


M. Stephens Jr. and T. Unayama: Child Benefit Payments and Household Wealth Accumulation

TABLE 4

The impact of child benefits on financial assets

\begin{tabular}{|c|c|c|c|c|c|c|}
\hline & (1) & (2) & (3) & (4) & (5) & (6) \\
\hline Child benefits received to date & $\begin{array}{l}0.64 * * \\
(0.27)\end{array}$ & $\begin{array}{l}0.68 * * \\
(0.27)\end{array}$ & $\begin{array}{l}0.60 * * \\
(0.29)\end{array}$ & $\begin{array}{l}0.66 * * \\
(0.22)\end{array}$ & $\begin{array}{l}0.53 * * * \\
(0.25)\end{array}$ & $\begin{array}{l}0.54 * * \\
(0.25)\end{array}$ \\
\hline Expected future child benefits & & $\begin{array}{l}-0.50^{* * *} \\
(0.12)\end{array}$ & & $\begin{array}{c}-0.40^{* *} \\
(0.13)\end{array}$ & & $\begin{array}{l}-0.60^{* * * *} \\
(0.17)\end{array}$ \\
\hline$p$-value test difference equals 1 & & 0.60 & & 0.86 & & 0.67 \\
\hline Maximum age of the oldest child & 13 & 13 & 12 & 12 & 14 & 14 \\
\hline$N$ & 22,543 & 22,543 & 21,449 & 21,449 & 23,623 & 23,623 \\
\hline
\end{tabular}

Notes: This table reports estimates based on Equation (8) using the level of financial assets as the outcome. All columns report ordinary least squares regression results and include survey year indicators, survey month indicators, a home ownership indicator and indicators for the age of the household head. In addition, each column includes separate number of children of variables for each age from 0 to the maximum age of the oldest child. Standard errors are robust to heteroskedascity. *** and **represent significance at the 1 and $5 \%$ level, respectively.

\section{Results}

Table 4 presents our main regression results based on Equation (8). ${ }^{14}$ Column (1) presents the results from the "naive" specification in which we include child benefits paid to date, $P B_{t}$, but exclude expected future benefits, $F B_{t}$. These results indicate that roughly half of the child benefits received to date have been spent. We can reject the null hypothesis that the coefficient is one; that is, that households save their entire child benefit payments.

As shown in Equation (7), however, the correct specification should include expected future benefits, $F B_{t}$ along with $P B_{t}$. As shown in column (2) of Table 4, when we include $F B_{t}$ the coefficient on $P B_{t}$ is effectively unchanged, again indicating that households spend roughly half of the child benefits. We find a negative and significant coefficient on expected future benefits, which is consistent with the theoretical predictions that higher expected future benefits lead to lower levels of current asset holdings. ${ }^{15}$

Another prediction of the model found in Equation (7) is that the difference between the coefficients on $P B_{t}$ and $F B_{t}$ equals one. This difference between these coefficients, shown in column (2), is $0.68-(-0.50)=1.18$. Given that the $p$-value for this test, also shown in Table 4 , is 0.60 , we cannot reject the null hypothesis that the difference is equal to one, as implied by the theory.

The estimates also allow us to determine the relevant time horizon over which households are making their decisions. Combining the theoretical model with our findings in the second column of Table 4 , we estimate that $-t / T=-0.50$. Assuming that households begin spending child benefits in a manner consistent with the model upon the birth of their oldest child, we can estimate $t$ using the average age of the oldest child, which is approximately 6 years of age based on the summary statistics shown in Table 2. Using these results, we

14 We only present the estimates for the coefficients on $P B_{t}$ and $1 F B_{t}$ in the tables below. The full results with the estimated coefficients on the remaining regressors are available from the authors upon request.

15 The relative small change in the coefficient on $P B_{t}$ when $F B_{t}$ is included suggests that the correlation between these two variables, conditional on the other variables in the model, is rather small. In fact, estimating a specification similar to Equation (8) except using $F B_{t}$ as the outcome yields a coefficient of 0.07 on $P B_{t}$. 
estimate that $T=12$, which is roughly the average period over which households in our sample receive child benefits. However, this finding is relatively small given that the average age of household heads is 35 in our sample and the model predicts these benefits will be spent evenly over the remainder the household's lifetime. We return to this finding below.

The remaining columns in Table 4 present our results when we vary the cutoff age for the oldest child from 13 to either 12 (columns (3) and (4)) or 14 (columns (5) and (6)). Not surprisingly, the point estimates remain qualitatively unchanged as the sample size changes. In addition, we continue to fail to reject the restriction that the difference between the two primary parameters of interest equals one.

The remaining prediction from Equation (7) that we test is that the coefficients on $P B_{t}$ and $F B_{t}$ systematically change as the household ages. The model predicts that the coefficient on cumulative benefits, $(1-(t / T))$, is one when children are first born and then linearly falls to zero. The model also predicts that the coefficient on future benefits, $-(t / T)$, begins at zero and linearly moves to -1 with $t$.

We estimate a modified household asset equation

$$
A_{i, t}=\alpha+Z_{i, t} \gamma+\delta_{1} P B_{i, t}+\delta_{2} P B_{i, t} \cdot t+\phi_{1} F B_{i, t}+\phi_{2} F B_{i, t} \cdot t+\varepsilon
$$

where the model predicts that when children are first born $\delta_{1}=1$ and $\phi_{1}=0$ and that, as the children age, the impact of the benefits are becoming more negative; that is, $\delta_{2}<0$ and $\phi_{2}<0 .{ }^{16}$

Two difficulties arise in empirically testing these predictions involving the change in the coefficients with age. First, benefit payments begin in the first period so an appropriate age measure should begin when families first have children. From that standpoint, the age of the oldest child in the household is the most appropriate measure of $t$. To examine the robustness of our results, we also use the average age of all children in the household and the age of the youngest child as measures of $t$. Second, there is bound to be a high degree of collinearity between the benefit measures and the interactions of these measures with the child age measures.

Our results from estimating Equation (9), shown in Table 5, yield mixed evidence for these predictions. As mentioned above, the different columns in the table correspond to different measures of child age. In column (1), when using the age of the oldest child to measure $t$, we cannot reject the null hypotheses that the main effects on $P B_{t}$ and $F B_{t}$ are one and zero, respectively. However, the standard errors are quite large on these estimates. ${ }^{17} \mathrm{We}$ also find that the interaction terms both have negative coefficients, as predicted by the model, with the coefficient on the interaction term for future benefits being marginally significant. ${ }^{18}$ The results using average child age shown in column (2) are qualitatively

16 More specifically, the model predicts that $\delta_{2}=\phi_{2}=-(1 / T)$ under the assumption that $T$ is the same for all households. Given the heterogeneity in $T$ across households, we only test the prediction that these coefficients are negative.

17 Because $P B_{t}$ is increasing in child age, the difficulty in separately identifying the effects of $P B_{i, t}$ from those of $P B_{i, t} \cdot t$ is reflected by the increase in the standard errors on the estimates shown in Table 5 as compared to those in Table 4. The same difficulty arises for the estimates corresponding to $F B_{i, t}$. While these estimates are lacking precision, they are still identified due to the legislative changes in both benefit amounts and the number of years that households are eligible for benefit payments.

18 We also cannot reject the null hypothesis that the coefficients on the interaction terms are equal. 
M. Stephens Jr. and T. Unayama: Child Benefit Payments and Household Wealth Accumulation

TABLE 5

The impact of child benefits on financial assets, including interaction terms

\begin{tabular}{lccc}
\hline \hline & $(1)$ & $(2)$ & $(3)$ \\
\hline Child benefits received to date & 0.35 & -0.16 & 0.10 \\
& $(0.80)$ & $(0.85)$ & $(0.43)$ \\
Child benefits received to date * Child age & 0.05 & $(0.10)$ & $0.13^{*}$ \\
Expected future child benefits & $(0.07)$ & -0.10 & $(0.07)$ \\
Expected future child benefits * Child age & -0.18 & $-0.24)$ & $(0.21)$ \\
Child age measure & $-0.04^{*}$ & $(0.04)$ & -0.07 \\
& $(0.03)$ & Average & Youngest \\
& Child age & Child age & Child age \\
\hline
\end{tabular}

Notes: This table reports estimates based on Equation (8) using the level of financial assets as the outcome. All columns report ordinary least squares regression results and include survey year indicators, survey month indicators, a home ownership indicator, and indicators for the age of the household hold. In addition, each column includes separate number of children of variables for each age from 0 to the maximum age of the oldest child. Standard errors are robust to heteroskedascity. *represents significance at the $10 \%$ level. All columns use 28,290 observations.

TABLE 6

The impact of child benefit on financial asset portfolio

\begin{tabular}{|c|c|c|c|c|c|c|c|}
\hline & \multicolumn{7}{|c|}{ Dependent variable: } \\
\hline & $\begin{array}{l}\text { Normal } \\
\text { deposit } \\
\text { (1) }\end{array}$ & $\begin{array}{l}\text { Time } \\
\text { deposits } \\
(2)\end{array}$ & $\begin{array}{c}\text { Insurance } \\
\text { (3) }\end{array}$ & $\begin{array}{l}\text { Equity } \\
\text { (4) }\end{array}$ & $\begin{array}{c}\text { Loan } \\
\text { trust } \\
(5)\end{array}$ & $\begin{array}{l}\text { Bond including } \\
\text { investment trust } \\
\text { (6) }\end{array}$ & $\begin{array}{l}\text { Other } \\
\text { (7) }\end{array}$ \\
\hline $\begin{array}{l}\text { Child benefits received } \\
\text { to date }\end{array}$ & $\begin{array}{l}-0.22 * * * \\
(0.04)\end{array}$ & $\begin{array}{l}0.26 * * * \\
(0.09)\end{array}$ & $\begin{array}{l}0.38^{* * *} \\
(0.07)\end{array}$ & $\begin{array}{l}0.12 * * * \\
(0.03)\end{array}$ & $\begin{array}{c}0.01 \\
(0.01)\end{array}$ & $\begin{array}{l}0.07 * * * \\
(0.02)\end{array}$ & $\begin{array}{l}0.12 * * * \\
(0.02)\end{array}$ \\
\hline $\begin{array}{l}\text { Expected future child } \\
\text { benefits }\end{array}$ & $\begin{array}{l}0.10^{* * * *} \\
(0.03)\end{array}$ & $\begin{array}{l}-0.23 * * * \\
(0.06)\end{array}$ & $\begin{array}{l}-0.30^{* * *} \\
(0.05)\end{array}$ & $\begin{array}{l}-0.03 \\
(0.02)\end{array}$ & $\begin{array}{c}-0.01 \\
(0.01)\end{array}$ & $\begin{array}{c}-0.01 \\
(0.01)\end{array}$ & $\begin{array}{l}-0.03 * * \\
(0.01)\end{array}$ \\
\hline Average share $(\%)$ & 28.4 & 30.5 & 32.9 & 2.1 & 0.3 & 0.9 & 4.1 \\
\hline Share for zero $(\%)$ & 15.0 & 31.1 & 30.5 & 89.9 & 98.7 & 95.6 & 82.5 \\
\hline
\end{tabular}

Notes: This table reports estimates based on the specification in Table 4. The dependent variable is the total financial asset holding in the category shown at the top of each column. All specifications use the sample where the age of the oldest child is 13 . Standard errors are robust to heteroskedascity. All columns report seemingly unrelated regression results. $* * *$ and $* *$ represent significance at the 1 and $5 \%$ level, respectively.

similar, although the interaction term for cumulative benefits is positive but insignificant. The results using the youngest child age shown in column (3) are the least consistent with the model, although, as we note above, the age of the oldest child is the most appropriate measure of $t$.

Next, we examine the impact of child benefits on the distribution of financial holdings in Table 6. The JFIES collects financial holdings separately for a number of asset categories. We find significant effects of child benefit payments across nearly all of these categories. Interestingly, the biggest effects are in "time deposits", "life insurance" and "equities", all of which are illiquid to some extent. These findings are consistent the Cabinet Office's survey findings (which we discuss in the Introduction), in which nearly half of households report saving the child benefit for their children's future. Surprisingly, 
TABLE 7

The impact of child benefits on financial assets by income level

\begin{tabular}{|c|c|c|c|c|}
\hline & (1) & (2) & (3) & (4) \\
\hline & Above median & Below median & Above $25 p$ & Below $25 p$ \\
\hline \multirow[t]{2}{*}{ Child benefits received to date } & $1.06 * *$ & -0.30 & $0.74 * *$ & -0.29 \\
\hline & $(0.43)$ & $(0.26)$ & $(0.33)$ & $(0.33)$ \\
\hline \multirow[t]{2}{*}{ Expected future child benefits } & -0.13 & $-0.57 * * *$ & $-0.47 * *$ & $-0.57 * *$ \\
\hline & $(0.26)$ & $(0.18)$ & $(0.21)$ & $(0.26)$ \\
\hline$p$-value test difference equals 1 & 0.72 & $0.03 * *$ & 0.60 & $0.10^{*}$ \\
\hline$N$ & 11,269 & 11,274 & 16,905 & 5,638 \\
\hline
\end{tabular}

Notes: This table reports estimates based on Equation (8) using the level of financial assets as the outcome. All columns report ordinary least squares regression results and include survey year indicators, survey month indicators, a home ownership indicator and indicators for the age of the household hold. In addition, each column includes separate number of children of variables for each age from 0 to the maximum age of the oldest child. All specifications use the sample where the age of the oldest child is 13. Standard errors are robust to heteroskedascity. $* * *, * *$ and $*$ represent significance at the 1,5 and $10 \%$ levels, respectively. p, percentile.

we find opposite signed results for normal deposits, which are the most liquid form of assets. Because we find that overall wealth is increased due to higher child benefits, one possible explanation for this last finding is that child benefit increases may lead parents to concentrate on more illiquid assets that have also have higher rates of return. Unfortunately, we are unable to investigate this possibility any further with the data at hand.

Finally, we examine the impact of liquidity constraints on our predictions for wealth accumulation in Equation (7). First, because liquidity constraints raise the marginal utility of consumption, households will increase current spending in an attempt to smooth the marginal utility of consumption between periods (Zeldes, 1989a). This inability to smooth consumption across periods eliminates savings out of past benefits and yields a coefficient on $P B_{t}$ of zero. Second, higher future benefits further hinder the ability of households to smooth consumption across periods. However, given that constrained households will already have reduced their savings to zero (under our assumption that future income is known), we would not expect higher future benefits to affect savings and, thus, anticipate a coefficient on $F B_{t}$ of zero. Third, we no longer expect the difference between the estimated coefficients on $P B_{t}$ and $F B_{t}$ to equal one.

Following Zeldes (1989a), we split our sample between likely unconstrained and constrained households. Because assets are our outcome of interest, we split the sample based on the household's income in their yearly income, which is a measure collected at the first interview and corresponds to the 12 months prior to this interview. To account for income growth both over the business cycle and over the life cycle, we rank households based on the income within calendar year-age cells. ${ }^{19}$

Our empirical investigation into the role of liquidity constraints is shown in Table 7. While we present results for sample splits both at the median (columns (1) and (2) of Table 7) and the 25th percentile (columns (3) and (4)) of yearly income, we focus our discussion on the findings around the median as we find similar qualitative results at the 25 th percentile. For households above the median income, we see that the coefficient on $P B_{t}$ is not significantly different than one, implying that most of the child benefits are saved.

19 We define age based on 5-year age bands: $25-29,30-34$ etc. 
In addition, using the estimated coefficient on $F B_{t}$ of -0.13 to infer the time horizon, we back out an estimate of $T=46$, which is nearly four times as large as our estimate of $T=$ 12 that we found with the full sample. ${ }^{20}$ Finally, we cannot reject the hypothesis implied by the model that the difference between the coefficients on $P B_{t}$ and $F B_{t}$ equals one for the unconstrained sample.

We find strikingly different results for our constrained sample. First, the coefficient on $P B_{t}$ is not significantly different from zero, which is consistent with the prediction that constrained households will consume all of their child benefit payments as they are received. Second, we find a negative and significant effect of future benefits on current savings among the constrained group, which runs contrary to our prediction. However, if future income is uncertain (as opposed to the assumption in our framework), liquidity constrained households may still hold some assets to protect against future negative income shocks (e.g. if income draws can possibly equal zero in all future periods). Because higher future benefits increase the marginal utility of current consumption of constrained households, these increases may raise the willingness of constrained households to take on current debt when income is uncertain. Thus, while the negative coefficient on $F B_{t}$ is inconsistent with our prediction, this finding may be consistent with a model that incorporates uncertainty. Third, as we predicted, we reject the hypothesis that the difference between the coefficients on $P B_{t}$ and $F B_{t}$ equals one. Overall, our findings confirm that the wealth response to child benefit payments differs between liquidity-constrained and unconstrained households.

\section{Conclusion}

While much of the previous literature on child benefit payments examines the immediate impacts on fertility and child well-being, we investigate the impact on wealth accumulation due to transitory (from a life-cycle perspective) transfer payments. Unlike much of the prior literature, we derive and test implications of the life-cycle/permanent income hypothesis for the impact of transitory income on wealth accumulation. As such, our paper also contributes to the literature that tests whether household consumption and savings behaviour is consistent with this model. As opposed to the dominant Euler equation approach, which can only examine whether consumption increases at the time benefits are received, by examining the effects on wealth we can examine the long-run implications of the theory on consumption and savings behaviour.

Consistent with the theoretical model, we find that past benefit payments increase current savings while expected future payments lower accumulated wealth. We cannot reject the restriction that the difference between the coefficients on accumulated and future benefit payments equals one. Moreover, we find evidence consistent with the prediction that the effects of past and future benefit payments vary over the life cycle. While this last finding holds for our preferred use of the age of the oldest child as the measure of the household's point in the life cycle, the evidence is mixed when using alternative measures of household age. Finally, our findings demonstrate that, as predicted by the model, the response of wealth accumulation to child benefit payments differs for liquidity-constrained and unconstrained households.

\footnotetext{
20 We continue to use $t=6$ based on the average age of the oldest child in the sample.
} 
We do not test whether child benefit payments are subject to a "flypaper effect"; that is, whether the additional household income due to these payments is spent entirely on child-related items. While the life-cycle model treats all income payments as fungible, policy-makers may be interested in knowing whether these benefits are spent on childrelated consumption. Such an investigation is beyond the scope of this paper. However, an analysis of this type would be quite challenging because it not only must examine spending changes at the time benefits are received but across all future years because we find that these benefit payments are saved as predicted by the life-cycle/permanent income hypothesis for unconstrained households.

\section{Acknowledgements}

A part of this study was done as a research project at RIETI. This study was financially supported by JSPS KAKENHI Grant Number 22730226, 15H03357. We would like to thank an anonymous referee and the Editor for their helpful comments. We also thank the Statistical Bureau of the Japanese Government for allowing access to the Family Income and Expenditure Survey data.

Final version accepted 27 September 2014.

\section{REFERENCES}

Barro, R. J. (1974) “Are Government Bonds Net Wealth?”, The Journal of Political Economy, Vol. 82, No. 6, pp. 1095-1117.

Browning, M. and T. F. Crossley (2001) "The Life-Cycle Model of Consumption and Saving”, Journal of Economic Perspectives, Vol. 15, No. 3, pp. 3-22.

Campbell, J. Y. (1987) "Does Saving Anticipate Declining Labor Income? An Alternative Test of the Permanent Income Hypothesis", Econometrica: Journal of the Econometric Society, Vol. 55, No. 6, pp. 1249-1273.

Carroll, C. D. (1997) "Buffer-Stock Saving and the Life Cycle/Permanent Income Hypothesis", The Quarterly Journal of Economics, Vol. 112, No. 1, pp. 1-55.

Cohen, A., R. Dehejia and D. Romanov (2013) "Financial Incentives and Fertility", The Review of Economics and Statistics, Vol. 95, No. 1, pp. 1-20.

González, L. (2013) "The Effect of a Universal Child Benefit on Conceptions, Abortions, and Early Maternal Labor Supply", American Economic Journal. Economic Policy, Vol. 5, No. 3, pp. 160-188.

Japan Times (2010) "About 50\% of Parents Plan to Sock Away Child Benefit Allowance: Survey", Japan Times, 1 May 2010. [Cited 16 August 2015.] Available from URL: http://www.japantimes.co.jp/news/2010/05/ 01/national/about-50-of-parents-plan-to-sock-away-child-benefit-allowance-survey/\#.Ue2am5VptN0

Jappelli, T. and L. Pistaferri (2010) "The Consumption Response to Income Changes", Annual Review of Economics, Vol. 2, No. 1, pp. 479-506.

Milligan, K. (2005) "Subsidizing the Stork: New Evidence on Tax Incentives and Fertility", The Review of Economics and Statistics, Vol. 87, No. 3, pp. 539-555.

_ and M. Stabile (2009) "Child Benefits, Maternal Employment, and Children's Health: Evidence from Canadian Child Benefit Expansions", The American Economic Review, Vol. 99, No. 2, pp. 128132.

— and - (2011) "Do Child Tax Benefits Affect the Well-being of Children? Evidence from Canadian Child Benefit Expansions", American Economic Journal. Economic Policy, Vol. 3, No. 3, pp. 175-205.

Stephens, M., Jr and T. Unayama (2011) "The Consumption Response to Seasonal Income: Evidence from Japanese Public Pension Benefits", American Economic Journal. Applied Economics, Vol. 3, No. 4, pp. 86-118.

- and - (2012) “The Impact of Retirement on Consumption in Japan", Journal of the Japanese and International Economies, Vol. 26, No. 1, pp. 62-83.

— and — (2015) "Estimating the Impacts of Program Benefits: Using Instrumental Variables with Underreported and Imputed Data", NBER Working Paper No. w21248. 
M. Stephens Jr. and T. Unayama: Child Benefit Payments and Household Wealth Accumulation

Van Lancker, W., J. Ghysels and B. Cantillon (2012) "An International Comparison of the Impact of Child Benefits on Poverty Outcomes for Single Mothers”, Centre for Social Policy Working Paper No. 12/03.

Zeldes, S. P. (1989a) "Consumption and Liquidity Constraints: An Empirical Investigation", The Journal of Political Economy, Vol. 97, No. 2, pp. 305-346.

(1989b) "Optimal Consumption with Stochastic Income: Deviations from Certainty Equivalence", The Quarterly Journal of Economics, Vol. 104, No. 2, pp. 275-298. 